\title{
DECIDIR E ARGUMENTAR: RACIONALIDADE DISCURSIVA E A FUNÇÃO CENTRAL DO ARGUMENTO
}

\author{
DECIDING AND ARGUING: DISCURSIVE RATIONALITY AND THE CENTRAL \\ FUNCTION OF ARGUMENT
}

\author{
Fabiano Hartmann Peixoto* \\ Claudia Rosane Roesler** \\ Debora Bonat ${ }^{* * *}$
}

\begin{abstract}
RESUMO
A temática da justificação e correção das decisões judiciais colocou um interesse ainda maior pela compreensão das conexões entre decidir e argumentar. Seriam possíveis e identificáveis as interrelações entre a argumentação jurídica e o direito? Qual seria o papel do argumento no discurso jurídico? Inicialmente, ante a complexidade na definição dos contornos do direito, haveria oportunidades a uma postura de complementaridade entre direito e argumentação jurídica. A partir disso desenvolveu-se o presente trabalho, pelo método dedutivo. Para tanto, utilizaram-se centralmente elementos teóricos apresentados por Manuel Atienza, Klaus Günther, Neil MacCormick e Robert Alexy. O objetivo foi compreender as propostas da argumentação jurídica e, na pesquisa, os autores dedicaram-se à análise teórica da argumentação jurídica e de sua inter-relação com o direito contemporâneo, verificando as suas inter-relações e o papel argumentativo na construção das justificações das opções decisórias. O presente trabalho compõe uma pesquisa mais ampla, com vistas a permitir a criação e/ou aplicação de modelos de análise e avaliação das decisões jurídicas.
\end{abstract}

\section{PALAVRAS-CHAVE}

Princípios. Argumentação jurídica. Racionalidade. Decisão judicial.

\begin{abstract}
The theme of justification and correction of judicial decisions has led to an even greater interest in understanding the connections between deciding and arguing. Would be possible and identifiable the interrelationships between legal argument and Law? What is the function of the argument in the legal discourse? Initially, given the complexity in defining the outline of Law, there would be opportunities to a complementary stance between Law and legal arguments. In such scenario, this paper was developed in a deductive fashion, by centrally using theoretical elements presented by Manuel Atienza, Klaus Günther, Neil MacCormick and Robert Alexy. The objective was to understand the proposals of legal argumentation, its interrelationship with contemporary Law, and its argumentative role in the construction of justifications for decision options. This work is part of a larger study, which aims to enable the creation and/or implementation of models for analysis and evaluation of legal decisions.
\end{abstract}

\footnotetext{
* Doutor em Direito pela UnB. Professor Adjunto na Faculdade de Direito da UnB (Brasília, DF, Brasil). E-mail: fabiano_hp@hotmail.com

** Doutora em Direito pela Universidade de São Paulo (USP). Professora na Faculdade de Direito da UnB (Brasília, DF, Brasil).E-mail: roeslerclaudia17@gmail.com

*** Doutora em Direito pela UnB. Mestre em Direito pela Universidade Federal de Santa Catarina - UFSC. Professora e Coordenadora de Pesquisa na Cesusc (Florianópolis, SC, Brasil).E-mail: debora_bt@hotmail.com
} 


\section{KEYWORDS}

Principles. Juridical argumentation. Rationality. Judicial decision.

\section{INTRODUÇÃO}

Seriam possíveis e identificáveis as inter-relações entre a argumentação jurídica e o Direito, especialmente no aspecto argumentativo da decisão judicial? Partindo-se de uma identificação proposta por Atienza (2013), uma concepção de Direito vem a ser um conjunto de respostas a questões básicas, tais como: quais seriam seus componentes básicos, como se determinaria o Direito válido, quais as relações mantidas com a moral e com a política e em que consistiriam as operações de interpretação e aplicação do Direito. Do século XX para hoje, dentro de uma cultura jurídica ocidental, podem-se agrupar as concepções nos seguintes termos: normativismo positivista, realismo jurídico, jusnaturalismo, as chamadas teorias críticas do Direito e pós-positivismo. Para a elaboração do presente trabalho foram feitas, portanto, algumas opções de partida - entre elas, acreditar na possibilidade de construção racional das opções decisórias, bem como na estruturação procedimental de tal construção. Com isso, é possível verificar um problema: as opções casuísticas ${ }^{1}$, associadas ao uso de estratégias para conferir uma aparência de racionalidade à escolha. Por isso seria muito interessante verificar a compatibilidade teórica entre a argumentação jurídica e as premissas da previsibilidade e segurança e, nesse particular, com possibilidades de se enfrentar a irracionalidade nas relações decorrentes do conflito, no qual há demanda deliberativa, e sua estruturação pelo Direito.

Para o desenvolvimento das opções teóricas aqui adotadas, serão utilizados referenciais de autores que visualizam problemas e até limitações nas teorias chamadas institucionais. Assim, haveria espaço para convivência complementar nas teorias institucionais conscientes da tensão entre universal e local, do conflito de facções e dos próprios limites do constitucionalismo, que demandam (ao menos em situações limite) uma atividade deliberativa, com espaço para a argumentação jurídica.

O objetivo desse trabalho não é um enfrentamento de outras propostas teóricas, o que importaria um desvio de rumo do marco teórico, mas o reconhecimento das possibilidades apresentadas pela argumentação jurídica. Com esse referencial, é importante a compreensão de relevantes comunicações entre Direito e argumentação jurídica.

\footnotetext{
${ }^{1}$ Embora se saiba que o marco teórico do presente trabalho considera as peculiaridades do caso concreto, por opção casuística não se entende o resultado de uma ação que buscaria a resolução do problema de uma certa e determinada pessoa (o que seria um aspecto positivo), mas uma opção que não suportaria o exercício/teste argumentativo, uma opção arbitrária baseada em uma opinião não suportada no exercício de racionalidade (aspecto negativo).
} 


\section{OPORTUNIDADES ENTRE DIREITO E ARGUMENTAÇÃO JURÍDICA}

O recurso a uma analogia matemática é útil para compreender a relação entre Direito e argumentação jurídica, ou melhor, o espaço que existe para a argumentação jurídica na compreensão do Direito. Dentro da lógica matemática, têm-se as chamadas condições necessárias e suficientes. As condições necessárias e suficientes impõem uma obrigatoriedade lógica, conferem um elevado grau de segurança e permitem o estabelecimento de relações de identidade. É possível identificar que algumas definições (D) têm certas características necessárias (CN) e que algumas características são próprias e exclusivas de algumas definições, isto é, são suficientes (CS). A matemática explica que se CN é condição necessária para que algo (X) seja uma definição (D), se (X) não for (CN), necessariamente não será (D), e se (X) for (D), necessariamente (X) será (CN). Pelo mesmo raciocínio, se (CS) é condição suficiente para que algo (X) seja uma definição (D), então, se (X) for (CS), será (D). Esse raciocínio é fundamental para a compreensão da existência de uma relação de identidade. Assim, ter a assinatura de um advogado é condição necessária para algo ser uma petição. Se pretendo verificar se algum texto é uma petição, posso iniciar minha pesquisa verificando se possui assinatura de um advogado. Mas, ao verificar a existência de um texto assinado por um advogado, não teria a certeza de se tratar de uma petição, pela ausência de suficiência.

Assim, para se definir algo ou orientar o raciocínio para a compreensão dos fenômenos de uma maneira geral, também é importante a condição suficiente. Isso pode ser ilustrado na seguinte proposição hipotética: - se o tempo esta semana estiver nublado, então a apresentação será no ginásio coberto. Tendo, nesse raciocínio, que a proposição ('p’) (“se o tempo esta semana estiver nublado”) implica ('q’) (“a apresentação será no ginásio coberto”), observa-se que ‘p’ é condição suficiente para 'q' (“esta semana é suficiente que esteja nublado para a apresentação ser no ginásio coberto”): p $\rightarrow$ q. Assim, tal raciocínio é inegavelmente útil para a construção de definições e identidades, mas consideravelmente limitado em seu alcance, uma vez que nem tudo que é assinado por advogado é uma petição, ou que a apresentação pode se dar com o ginásio coberto por outros motivos. Essa relação matemática de suficiência e necessidade não encontraria facilidade para explicação do Direito; contudo, ela pode ser muito útil para demonstrar limitações na identificação do Direito por modelos teóricos que buscam atribuir a ele uma explicação necessária ou suficiente.

Uma opção de divisão de perspectivas de compreensão sobre o Direito poderia ser a seguinte: entendê-lo pelo estudo das normas 'p1', como uma prática dos operadores do direito 'p2' ou pelo ideal de Direito/visão crítica ‘p3’.

Contudo, de pronto, haveria uma dificuldade a uma resposta a um exercício lógico de suficiência ou necessidade, no qual ‘q’ seria: “permite-nos a compreensão do direito”. Tal exercício 
apresenta especiais dificuldades a uma precisão no seu conceito. Se, contemporaneamente, é consenso que as preocupações conceituais estão minimizadas, a simples aplicação da "prova real" desse raciocínio apontaria para uma dificuldade de delimitação do universo do Direito a ser compreendido ('p1', 'p2’ ou 'p3’) - essa uma preocupação importante atualmente. A perspectiva da argumentação jurídica leva isso em conta, sem excluir as perspectivas apontadas acima e - igualmente - sem pretensão de identidade entre Direito e argumentação jurídica, mas certa de que há uma inegável demanda deliberativa ao Direito. Nesse sentido, Atienza (2013) enumera cinco motivos do aumento da preocupação dos juristas com aspectos argumentativos da prática jurídica. São eles: 1) as teorias de Direito mais marcantes do século XX deixaram, por razões diversas, de cuidar dessa dimensão do Direito; 2) a prática do Direito parece consistir de modo relevante na argumentação (Atienza aponta para as imagens mais populares da prática jurídica, como o desenvolvimento dos julgamentos, nos quais é cada vez mais relevante a dimensão argumentativa); 3) a constitucionalização do Direito e outras mudanças nos sistemas jurídicos contemporâneos, que parecem levar a crescimento qualitativo e quantitativo em termos de exigência de fundamentação e argumentação das decisões dos órgãos públicos; 4) um ensino do Direito mais prático teria que estar voltado ao manejo essencialmente argumentativo do material jurídico e 5) na sociedade contemporânea, percebe-se uma perda da importância da autoridade e da tradição como fontes de legitimidade do poder e, em seu lugar, impõe-se a aceitação e o consentimento dos afetados. A democracia, sobretudo a democracia deliberativa, exige cidadãos capazes de argumentar racionalmente e competentemente sobre ações e decisões.

\section{ARGUMENTAÇÃO JURÍDICA NO ESPAÇO DELIBERATIVO}

Estruturalmente, a base de Toulmin (1958) permite compreender a argumentação como uma atividade voltada à propositura de pretensões e seus testes, colocando-as em xeque, respaldando-as, produzindo razões, questionando-as, refutando críticas e assim por diante. Assim, na base estão os argumentos, que possuem quatro elementos: a pretensão, as razões, a garantia e o respaldo. A pretensão é o ponto de partida e o ponto de chegada. As razões, os fatos específicos do caso. A garantia se estabelece por enunciados gerais e o respaldo é o elemento de reforço da garantia.

Assim, de uma pretensão partem questionamentos que demandam razões a favor da pretensão. Ato contínuo, podem ser demandadas garantias do argumento, que permitam ou autorizem a ida de um enunciado ao próximo. Pode haver a necessidade de se demonstrar que as garantias sejam válidas, relevantes e suficientes. Nesse caminho, a força do argumento também poderá variar, na 
medida em que a pretensão puder ser qualificada com presumidamente, plausivelmente, provavelmente, absolutamente, etc. (ATIENZA, 2002, p. 137). Essa ideia de caminho, em que há passos a serem seguidos, é igualmente fundamental para a compreensão da argumentação jurídica.

O procedimento argumentativo e as relações entre a argumentação moral e a argumentação jurídica também foram objeto da obra Teoria da argumentação no direito e na moral, de Klaus Günther (2011), que trata de quatro grandes temáticas: 1) o problema da aplicação na ética do discurso, na qual são tratados as relações da fundamentação e da aplicação e o problema do princípio da universalização no discurso; 2) o problema da aplicação de normas no desenvolvimento da consciência moral e os estágios no desenvolvimento de tipos de aplicação; 3) argumentações de adequação na moral, com o problema das normas prima facie e das normas definitivas; 4) argumentações de adequação no direito, inclusive sobre modelos hermenêuticos e a busca de uma melhor justificação.

Günther (2011) apresenta como tese central que o caminho para a equidade não está só em seguir princípios corretos, mas também em aplicá-los de forma imparcial, considerando-se todas as circunstâncias especiais existentes. Assim, para o autor, “[...] não é possível abdicar da razão prática.” (GÜNTHER, 2011, p. VII)

No entender de Günther (2011, p. VIII-35), nas fundamentações intersubjetivas deve-se supor que as razões de ações são compostas por duas dimensões: de validade e da aplicação, uma vez que não há normas que consigam regular todos os casos de sua aplicação. O dilema proposto por Kant (quando um perseguido pela polícia política se esconde em sua mesa Kant é posto em um dilema: dizer a verdade e entregá-lo à truculenta polícia política ou mentir e proteger o fugitivo) faz Günther desenvolver um discurso de justificação e um discurso de aplicação (MARTINS; OLIVEIRA, 2006, p. 244).

Assim, o princípio da universalização (“U”) precisa ser complementado pelo discurso² de aplicação, para se esgotar o sentido pleno da ideia de imparcialidade. O que é relevante para o discurso de justificação é a determinação do conteúdo semântico de uma norma, com o objetivo de testá-lo na universalidade da norma [norma que proíbe a mentira]. Ou seja, proibir a mentira é, em termos universais, passível de aceitação. Pode não ser importante antecipar particularidades nesse momento do discurso (MARTINS; OLIVEIRA, 2006, p. 244).

Os interesses das pessoas que participam do discurso são mutáveis, histórica e socialmente

\footnotetext{
${ }^{2}$ A expressão discursos é também utilizada no sentido da forma especializada em fundamentar pretensões válidas. “O sentido de validade da norma consiste, portanto, de um reconhecimento desta por todos, a saber, como participantes de um discurso prático.” (GÜNTHER, 2011, p. 35)
} 
circunscritos. Isto é, na justificação, conhecimento e tempo não necessariamente se confirmam como realidade (MARTINS; OLIVEIRA, 2006, p. 244).

A aplicação da norma a casos particulares é uma forma de discurso pautado, portanto, pela ética do discurso - princípios da não contradição, da consistência semântica, da veracidade, da simetria na participação dos sujeitos do discurso, etc. -, prevalecendo, como objetivo, o melhor conjunto argumentativo. O discurso de aplicação busca avaliar, no caso particular, os efeitos colaterais não antecipados ou desconsiderados no discurso de justificação (MARTINS; OLIVEIRA, 2006, p. 244-245).

Como produto, a argumentação tem por finalidade a geração de razões com consistência, por meio das quais uma pretensão de validade poderia ser rechaçada ou resgatada e se estabelece nos níveis lógico e semântico (ausência de contradição, consistência semântica na aplicação de predicados, identidades de significados entre falante e ouvinte, entre outros) (GÜNTHER, 2011, p. 35).

Günther (2011, p. 36) ainda sustenta que, como procedimento, argumentações são processos de entendimento, e os participantes ingressam em um discurso cooperativo em busca da verdade. Para ele,

[...] parte-se da preposição de reconhecimento mútuo de iguais direitos aos participantes, sem pressão de agir, com franqueza, buscando um consenso racionalmente motivado entre os participantes. A simetria discursiva deve ser tal que evite qualquer coação "senão a do melhor argumento". Para ele, discursos de aplicação são possíveis, porque a pretensão de validade se orienta dessa forma e, como discurso prático, está aberto a qualquer um.

O problema, ou, como Günther (2011, p. 36) coloca, uma variante do problema, é a observância geral de “U”. Como consequência, as normas teriam validade para mais de uma situação (essa seria uma propriedade da própria norma), e o problema seria perguntar: “[...] se a pretensão de validade se refere não só ao reconhecimento por todos os virtuais participantes do discurso, mas também a todas as circunstâncias em que a norma for aplicável.” Não podem ser previstas todas as situações de aplicação e todos os sinais relevantes para interesses presentes e futuros. Assim, não há possibilidade de estabelecimento de "U” como índice temporal e cognitivo vinculante da decisão. Como procedimento, a argumentação tem como característica uma progressão dialética ao infinito.

Assim, com uma visão de complementariedade ao sentido de “U”, Günther (2011, p. 37) propõe a possibilidade de concepção de um discurso de aplicação, que carregaria o sentido de imparcialidade, mas que tivesse como tema a "[...] adequação de uma norma a uma circunstância, em consideração a todos os sinais característicos da situação de aplicação.” Ocorreria um “entrecruzamento dialético" entre a validade geral e os contextos concretos, recontextualizando a 
norma $^{3}$.

Para Günther, o discurso de aplicação (2011, p. 156-157) apresenta aplicação e validade se relacionando de forma estratificada. Assim, haverá uma progressiva conformação da aplicação, inicialmente relacional, do que chama ego e alter, em que há apenas expectativas de identificação da distinção entre validade e aplicação ao se adotar a perspectiva do outro. A seguir, numa espécie de movimento centrífugo, a observação se dá de forma um pouco mais ampliada, com a visão de um terceiro (neutro), distante do contexto concreto, no plano de pessoas não afetadas ou atuantes (estágio de sistema de normas). Situação e norma já estão distintas, mas validade e adequação ainda não podem ser distinguidas. O terceiro estágio marca a ampliação do universo do outro, generalizado (consciência coletiva) para o universo do discurso, no qual as avaliações não se dão mais em referência a membros ou grupos, mas a todos.

Segundo Günther (2011, p. 157):

[...] com a desvalorização da validade particular e contextualmente relacionada da norma, a seleção de sinais característicos relevantes não é mais predeterminada, tampouco fixada antes da aplicação de uma norma. [...] A partir desse momento, todos os sinais característicos que, segundo a pluralidade de pontos de vista normativos, carecedores de justificação, puderem ser identificados como relevantes, poderão ser examinados. Já que validade não garante automaticamente mais adequação, essa adequação de uma norma em uma situação precisa primeiramente ser estabelecida sob consideração de todos os sinais característicos relevantes. [...] fundamentação e aplicação imparciais se tornam mutuamente correlacionadas para constituir o sentido de um juízo moralmente correto (válido e adequado).

Ao compreender que a aplicação imparcial de normas válidas é uma atividade comum, Günther (2011, p. 239-243) apresenta diferenças entre a ética do discurso e Direito e Moral. Assim, a fundamentação e aplicação, discursivamente construídas, apresentam o que é correto fazer, mas não garantem que aquilo que é correto fazer também se torne o que se quer fazer naquela situação, isto é, há o item da motivação ou o dever de efetivamente observar a norma:

[...] alter apenas se poderá demandar a observância de uma norma válida e situacionalmente adequada sob a condição de que, caso seja necessário por meio de recursos que produzam empiricamente uma decisão, ele possa postular que ego observe a norma.

Assim, “O Direito constitui uma relação entre os participantes virtuais do discurso cuja demanda mútua seja a observância efetiva das normas válidas.” Consequentemente, haverá o reconhecimento recíproco dos participantes como “sujeitos de direito”. A validade do princípio da reciprocidade será obtida por procedimentos em que há fixação de normas jurídicas que serão aplicadas por juízos orientados circunstancialmente e poderão ser impostas. Assim, haverá discursos

\footnotetext{
3 “Só depois de olhar para todos os lados, cautelosamente, é que, então, cada um deverá mergulhar no caso concreto, aqui e agora”. (GÜNTHER, 2011, p. 38)
} 
de fundamentação e aplicação institucionalizados, que pressupõem recursos de poder organizados em modelos procedimentais e decisões estruturadas em procedimentos claros com diretrizes igualmente já estabelecidas. Esses discursos serão legítimos na medida em que a argumentação neles estabelecida produza eficientemente as necessárias razões (GÜNTHER, 2011, p. 239-243).

\section{A RACIONALIDADE DISCURSIVA}

Um aprofundamento da compreensão acima pode ser feito mediante as próprias críticas. Existem críticas radicais a uma teoria do discurso. Uma objeção mais radical (como a formulada por Jacques Derrida e Jean-François Lyotard) rejeita a possibilidade de uma racionalidade. Para essa linha, a suposta racionalidade apenas encobriria o inevitável contextualismo ao se pretender justificar um princípio moral, isto é, expressões de variáveis da subjetividade tais como políticas, sociais, sexuais, etc. (MARTINS; OLIVEIRA, 2006, p. 242).

Um segundo grupo de objeção, menos radical, aceita uma racionalidade limitada, mas apenas no nível do reconhecimento dos fatos. A racionalidade estaria no “[...] saber sobre fatos ou sobre a escolha estratégica dos meios necessários para realizar algum objetivo humano, porém objetivos e finalidades sociais não estão sujeitos a uma escolha racional.” (MARTINS; OLIVEIRA, 2006, p. 242).

Uma objeção mais específica é a realizada à ética discursiva baseada no princípio da universalização, que permitiria a justificação de juízos morais. Para a linha crítica, em um mundo onde os sujeitos estão sempre limitados no tempo e no conhecimento, ainda que o princípio da universalização fosse aceito, não poderia estar presente adequadamente em uma disputa argumentativa moral (MARTINS; OLIVEIRA, 2006, p. 242).

A teoria do discurso admite que pode também ser racional a justificação de determinadas normas de comportamento. A tese de Günther, segundo Martins e Oliveira (2006, p. 242-243), é que a justificação e a aplicação de normas têm objetivos distintos e são orientadas por princípios específicos, e apenas a fundamentação de normas é orientada pelo princípio da universalização.

No plano da aplicação, pode surgir uma discordância fundamental entre Alexy ${ }^{4}$ e Günther. Havendo, durante a aplicação de uma norma prima facie válida, em que há a constatação da possibilidade de existência de uma outra norma prima facie igualmente válida (caso da promessa de ir a uma festa, mas não comparecer porque outro amigo, no mesmo horário, estava precisando de

\footnotetext{
${ }^{4}$ Embora seja possível tratar da sua teoria da argumentação jurídica, a dimensão espacial do trabalho não permitiria uma análise detida. Assim, serão feitas algumas considerações e, ao final, na lista de referências, a menção às obras do autor.
} 
ajuda, ou seja, em outras palavras: um comando estabelecendo que promessas devem ser cumpridas em oposição a outro comando, de que não se deve negar auxílio a um amigo em dificuldades), Günther não vê na ponderação um critério racionalmente verificável, pois para ele a ponderação indicaria apenas o que é melhor no caso e não o que é normativamente devido: “Auxiliar um amigo em necessidade é mais importante do que comparecer a uma festa porque, axiologicamente, simplesmente é assim. ” (MARTINS; OLIVEIRA, 2006, p. 245).

É importante registrar a ideia de Alexy ao tratar a ponderação: no entender preliminar do autor (1988, p. 149-150), a racionalidade na fundamentação jurídica sempre encontrou dificuldades por raciocínios muito extremos. De um lado, variantes subjetivistas, relativistas, decisionistas ou irracionalistas, e, de outro, objetivistas, absolutistas, cognocistivistas ou racionalistas, mas sempre na lógica do “tudo-ou-nada”. Alexy afirma ainda que não são possíveis teorias morais materiais que, para cada questão prática, permitam extrair uma resposta, mas são possíveis teorias morais procedimentais que formulem regras ou condições de argumentação para uma decisão prática racional. Assim, com um sistema de regras e princípios do discurso (propõe um conjunto de 28 regras), será assegurada a racionalidade da argumentação e de seu resultado.

Consequentemente, numa espécie de codificação de posturas, a razão prática pode ser complementada com regras específicas do discurso jurídico. Nisso está a base para a justificação e crítica das decisões e do sistema jurídico em seu conjunto (ALEXY, 1988, p. 150).

Em sua obra Conceito e validade do Direito, Alexy (2011) faz uma distinção sobre o problema conceitual do Direito em perspectiva entre a moral e o Direito: a ideia de separação (fundamental para as teses positivistas), na qual a preocupação está na conformidade com o ordenamento e na eficácia social, e a tese da vinculação (fundamental para as teses não positivistas), na qual o conceito de Direito deve levar em conta elementos morais. A tese da vinculação não exclui as duas preocupações da tese de separação (conformidade com o ordenamento e eficácia), mas as observa a partir de uma ótica de correção.

Essa ótica de correção é ilustrada por Alexy (2011, p. 6-7) com o exemplo do “injusto legal - não direito” da decisão sobre cidadania do Tribunal Constitucional Federal Alemão. Nessa decisão, o Tribunal considerou uma lei racista alemã, que privava da nacionalidade alemã os judeus emigrados, uma lei nula $a b$ initio. Tal decisão foi estabelecida em uma demanda individual (havia elementos para demonstrar tanto a legalidade, quanto a eficácia social para outros indivíduos), mas o Tribunal optou por considerar a nulidade total e $a b$ initio da lei, sob o fundamento de que

“[o] direito e a justiça não estão à disposição do legislador. [...] o Tribunal Constitucional Federal afirmou a possibilidade de negar aos dispositivos ‘jurídicos’ nacional-socialistas sua validade como direito [...] uma vez que eles contrariam os princípios fundamentais da 
justiça, de maneira tão evidente que o juiz que pretendesse aplicá-los ou reconhecer seus efeitos estaria pronunciando a injustiça, e não o direito (BVerfGE 3, 58 (119); 6, 132 (198))”.

O valor justo é caro a todos, e, ao tratar as questões práticas, a argumentação jurídica permite que se destaque essa preocupação, uma vez que, seguindo algumas posturas e regras do discurso jurídico, consegue-se produzir uma base para a justificação ou para a crítica, pela sua falta e descompasso com o sistema como um todo.

Especificamente quanto ao sistema de prioridades prima facie é importante a reflexão feita por Bustamante (2008, p. 248-251). O autor apresenta uma ideia de obrigação prima facie, não como algo com aparência de obrigação, mas algo mais próximo à capacidade de expressar a característica de superabilidade, no sentido de deixar de ser aplicada devido a exceções que possam surgir. Contudo, essa característica ainda diz respeito ao raciocínio de pressupostos e consequências, ou seja, no plano compatível com as normas hipotéticas de Kelsen ou das regras de Alexy. Assim, a diferença em relação aos princípios não está em ser uma obrigação prima facie, mas no estabelecimento gradual das consequências de aplicação. Bustamante (2008, p. 241) identifica um problema de estudo: “[...] Alexy introduz uma categoria de normas - os princípios, definidos como mandados de otimização, que devem ser cumpridos na máxima medida possível - que não podem ser definidos como 'hipotéticas'”, entretanto, raciocina:

[...] ao mesmo tempo, se amoldam à definição de 'norma jurídica' proposta por Kelsen, que - apesar de não ser idêntica - se assemelha substancialmente à do próprio Alexy. O problema é que para Kelsen (1950), só é possível imaginar duas categorias de normas sociais: as categóricas e as hipotéticas, sendo que apenas essas últimas podem ser aceitas como normas jurídicas válidas.” (BUSTAMANTE, 2008, p. 241)

Para Bustamante (2008, p. 242), Kelsen não chegou a conhecer a diferença entre obrigações próprias/absolutas e prima facie, tampouco chegou a se interessar por um conceito próximo ao que se entende por princípios.

Segundo Bustamante (2008, p. 243), norma seria, para Kelsen, um ato de prescrição, permissão ou faculdade de condutas. Tal ato, que impõe ao homem conduzir-se de determinada maneira, fora autorizado por outra norma preexistente que regula a forma com ela foi produzida. Kelsen também fazia a distinção entre a norma e o texto que a veicula, assim como para quem adota um conceito semântico de norma há diferença entre norma e enunciado normativo (texto), entre o texto e o significado do texto. Para Bustamante (2008, p. 243-244), a diferença entre Alexy e Kelsen é que o primeiro não acata elementos mentais (psicológicos ou voluntaristas), enquanto Kelsen os aceita, para ver na norma o sentido de um ato de vontade.

A dissonância entre Kelsen e Alexy estaria no caráter hipotético da norma do primeiro, pelo qual a norma apresenta descrições das condições de aplicação, algo incompatível com a visão de 
princípios como mandados de otimização. Não haveria a moldura hipotética normativa. A chave para a compatibilização do conceito de norma aos princípios seria a compreensão da noção de obrigação prima facie (BUSTAMANTE, 2008, p. 246).

Para Bustamante (2008, p. 254), “[a] diferença do caráter prima facie dos princípios está no fato de que as regras, para deixarem de ser cumpridas, necessitam que se introduza uma cláusula de exceção (Alexy, 1986, p. 100), o que não acontece com os princípios.” Pode-se dizer que os princípios possuem caráter prima facie mais marcantes, pois carregam em si maior grau de superabilidade (por princípios opostos na concretude). As regras, a seu turno, carregam a superabilidade em convergência com um caráter excepcional apenas.

Conclui Bustamante (2008, p. 255):

[...] tanto os princípios como as regras são normas, quer se use o conceito de norma de Kelsen ou de Alexy. Da mesma forma, tanto os princípios como as regras têm caráter prima facie, embora este seja mais acentuado nos primeiros. A diferença está na estrutura lógica: enquanto as regras contêm determinações concretas, os princípios se limitam a buscar um certo "estado ideal de coisas".

A construção teórica para a ponderação observa que, com grande frequência, o caráter principiológico das normas, especialmente as de direitos fundamentais, é manifestado, até mesmo de forma referencial, quando se fala em valores, objetivos ou regras sobre distribuição de algum ônus argumentativo (ALEXY, 2006 p. 86). Contudo, Alexy não nega - muito pelo contrário - a existência de regras, inclusive sob o ponto de vista da análise estrita de direitos fundamentais, em que há espaço inclusive para uma direta aplicação de um raciocínio dedutivo. Para a proposta de Alexy, tanto princípios quanto regras são normas e dizem o que deve ser. Ambas são expressões básicas do dever, da permissão e da proibição (ALEXY, 2006, p. 87).

Na compreensão do tema, é importante frisar, além do aspecto normativo, princípios como mandamentos de otimização, isto é, normas que não atuam sob a lógica binária do tudo ou nada, mas que ordenam a realização de algo na maior medida possível, observando-se as limitações e possibilidades fáticas e jurídicas existentes e vinculadas a condições de precedência. Tal compreensão é fundamental para o desenvolvimento de uma análise da argumentação jurídica.

Além da possibilidade de julgamentos legais e morais, com a constatação dos mandamentos de otimização, há uma outra possibilidade imposta à decisão: a necessidade de opções axiológicas com reflexos deontológicos, todos possíveis e que demandam mais uma atividade justificativa, colocando a opção decisória como a mais realizativa sob a ótica das possibilidades jurídicas e fáticas apresentadas ao caso.

A argumentação jurídica de Günther estabelece que obrigações definitivas apenas surgem 
após a consideração das circunstâncias relevantes, ou seja, após o resultado de um discurso de aplicação. Ao se buscar a máxima quantidade de possibilidades de se excepcionar uma norma relativamente precisa sobre algo podem surgir exceções normativas (o que não deixa de ser próximo ao caráter de exceção que o modelo de regras admite). Se essas normas estritas admitirem variações, a depender do caráter de cada caso concreto, isso parece muito próximo a admitir que na realidade tais normas estritas são desnecessárias (e uma base racional a isso igualmente parece desnecessária). Por outro lado, o discurso de aplicação está muito próximo à identificação de situações concretas e abstratas utilizadas no sopesamento e na fórmula do peso.

Neil MacCormick (2006) inicia sua obra Argumentação Jurídica e Teoria do Direito com a preocupação central que será objeto de reflexão até sua última obra, com publicação póstuma - a descrição e explicação de argumentos jurídicos, relacionando-os à teoria geral do direito, em uma estrutura da teoria geral da razão prática. Busca, assim, a aplicação da razão pelo homem para decidir entre possíveis escolhas.

No percurso, por força própria e pela colaboração de teses críticas, mantém a centralidade do tema, alterando, entretanto, algumas conclusões, as quais aqui, sem intenção exaustiva (o próprio MacCormick reconhece que revisões e reflexões sobre suas ideias iniciais estão espalhadas em conferências, debates e outras discussões), vão-se buscar ressaltar.

De início, MacCormick (2006, IX) já define o que operará como argumentação prática, ou seja, “[...] aplicação da razão por parte dos seres humanos para decidir qual é a forma correta de se comportarem em situações onde haja escolha.”

Da mesma forma, o autor compreende argumentação jurídica como uma forma ramificada da argumentação prática. Por reconhecer que os problemas de interpretação, de classificação e de pertinência, na argumentação a partir de normas, têm seus limites, e que o raciocínio dedutivo, portanto, não pode ser autossuficiente e autossustentável na justificação jurídica, MacCormick (2006) vê espaço para o desenvolvimento do raciocínio prático na solução desse problema.

Fazendo expressa concessão à teoria da argumentação jurídica de Alexy, MacCormick (2006) apresenta a argumentação como espécie do raciocínio prático, uma vez que algo que estabelece o que é correto fazer em situações de escolha tratará de justificação da escolha feita. Para isso, diferencia-se MacCormick de Alexy pela estratégia, pois, em análise mais fenomenológica, debruçase nas argumentações feitas pelos tribunais (especialmente Inglaterra e Escócia) - método da reconstrução racional, com marcante viés retórico.

Como marco filosófico, MacCormick, num primeiro momento, identificou-se com as teses do positivismo elaborado por H. L. A. Hart, apresentado no livro O conceito de Direito. Mas o próprio 
MacCormick (2006) confessa afastar-se do padrão positivista abrandado para o que ele chama de institucionalismo pós-positivista. Nesse caminho, reconhece as qualidades da lógica dos predicados, em vez da lógica das proposições inicialmente proposta.

Antes (discorre MacCormick em 1978) havia o pensamento de que, se a concepção de justiça é ou não boa ou sólida, isso dizia respeito aos princípios gerais da filosofia normativa do direito ou filosofia moral (MACCORMICK, 2006, p. 94), e esse seria um debate externo aos tribunais na maioria dos casos. Contudo, mesmo naquela época, MacCormick (2006, p. 127-129) já se inquietava com o problema da esgotabilidade normativa, o que, não raro, envolve o que chama justificação de segunda ordem, isto é, justificação de escolhas entre possíveis deliberações rivais. As deliberações jurídicas fixam comportamentos e ordenam consequências em face à verificação de determinadas condições. Apresentam um modelo para o mundo e não do mundo (MACCORMICK, 2006, p. 132). Disso, “[n]ão pode estar em questão se as deliberações jurídicas descrevem o mundo com precisão ou sustentam previsões verdadeiras sobre acontecimentos naturais” (MACCORMICK, 2006, p. 131).

Também é conveniente destacar que, quanto ao exame de princípios e coerência, MacCormick resiste às críticas, mas mantém posição sobre as críticas feitas a Ronald Dworkin acerca do conceito interpretativo do Direito, que muito se alinham à argumentação jurídica proposta por Klaus Günther.

É importante que MacCormick, assim como a teoria da argumentação de Robert Alexy, reconhecem a importância do discurso racional prático para uma justificação na argumentação jurídica, a partir, portanto, de exigências da razão geral prática, que submetem a argumentação jurídica aos princípios gerais da racionalidade prática. Entretanto, nuances de diferença são elaboradas nesse aprimoramento reflexivo de MacCormick, que o separam da teoria alexyana.

Para Atienza (2002), que apresentou crítica à teoria de MacCormick (visão de 1978) sobre o papel desempenhado pela lógica e a dedução, assim como sobre a dependência da verdade reconhecida pelo juiz ou pela decisão judicial que a estabeleça, visualiza-se um aprimoramento reflexivo, notadamente no enfoque dado à questão da qualificação e aos entraves submetidos à dedução nesse aspecto e à necessidade de argumentação retórica.

Para MacCormick, havendo problemas práticos, destacadamente existindo possibilidades decisionais justificáveis, os argumentos serão mais ou menos fortes se atrelados a valores, que igualmente não têm lugar na arbitrariedade, pois dizem respeito a condições de existência social da mesma forma boas, visto que estruturados sobre a mesma base valorativa que se reflete na estruturação principiológica de todo o ordenamento. Para MacCormick, o Direito é capaz de expressar a vontade de toda a sociedade. 
MacCormick reconhece a apresentação de Alexy, da argumentação jurídica como uma atividade linguística, que busca tratar da correção dos enunciados normativos. Há também expresso reconhecimento à tese do caso especial, isto é, da argumentação jurídica como um caso especial da argumentação prática geral (MACCORMICK, 2011, p. 172).

Sob uma teoria retórica da argumentação, MacCormick (2008) parte para a chamada justificação de segundo nível, o que significa o atendimento de alguns requisitos: a universalização, a consistência narrativa, a consistência normativa e o consequencialismo; ou seja, a relação entre a decisão e a comunidade.

Há também aí uma importante contribuição de MacCormick, referente ao problema (crítica) da possível falta de segurança jurídica fornecida pelas teorias da argumentação jurídica. Essa proposta de caminho é até mais compatível com a visão de segurança (ao menos em uma concepção mais atual) do que a exigência do caráter de universalidade do raciocínio, como forma de garantir a previsibilidade tão cara ao modelo de segurança jurídico histórico. MacCormick fundamenta, inclusive, a possibilidade de diálogo entre fenômenos universais (constitucionalismo como fundamento de previsibilidade) e locais (constitucionalismo aplicado).

Segundo MacCormick (2006), a razão prática pode não ter a infalibilidade no fornecimento das justificativas. A ênfase justificadora, segundo ele, deve ser repensada, visto que processos de descoberta racional precisam tanto de processos de justificação racional quanto de pensamentos reflexivos.

Atienza (2006, p. 182) condensa:

Dito de forma resumida, sua tese consiste em afirmar que justificar uma decisão num caso difícil significa, em primeiro lugar, cumprir o requisito da universalidade, e, em segundo lugar que a decisão em questão tenha sentido em relação ao sistema (ou seja, que cumpra os requisitos da consistência e da coerência) e em relação ao mundo (o que significa que o argumento decisivo - dentro dos limites marcados pelos critérios anteriores - é um argumento consequencialista).

Para MacCormick (2006, p. 131-133) as decisões jurídicas tratam do mundo real e, assim como as hipóteses científicas, elas devem fazer sentido não só no respectivo sistema como no mundo. Portanto, além do sentido dentro do próprio sistema jurídico, pelo modo consequencialista de argumentar, devem ser consideradas as consequências de se adotar uma deliberação, examinando e verificando hipóteses em comparação com outras hipóteses, em formato similar a testes científicos, isto é, exercícios de comparação e rejeição para verificação.

Sobre o modelo de MacCormick, Atienza (2006) também destaca que, sob a coerência qualificada como normativa, existem dois importantes tipos de argumentos para a solução dos casos difíceis - os argumentos a partir dos princípios e os argumentos por analogia. Se uma norma pode ser

Revista da Faculdade de Direito - UFPR, Curitiba, vol. 61, n. 3, set./dez. 2016, p. 213 - 231 
subsumida por um princípio, significa que ela é valiosa para uma justificação. Sua força, por óbvio, não é absoluta, e o seu caráter não é concludente, mas relevante e importante. Os argumentos por analogia são semelhantes, sobretudo porque são construídos. Para MacCormick, na justificação de uma decisão, além desses dois argumentos, são decisivos (como mencionado acima) os argumentos consequencialistas, afastando as decisões cujas consequências forem mais inaceitáveis, avaliadas em relação a uma série de valores, como o bem comum, o senso comum, a Justiça, a conveniência pública.

Ao estruturar uma teoria pelo uso de argumentos por princípios, assim como ao ampliar as exigências pela coerência, o resultado pretendido para que uma decisão seja considerada coerente ganha complexidade. Segundo Martins, Roesler e Jesus (2011, p. 219), “[...] ultrapassou-se a ideia de coerência apenas como um requisito formal de adequação entre o direito posto e o direito que aparece na solução de cada caso concreto.” Com MacCormick, “[p]assou-se a exigir a demonstração de que a solução construída é coerente com ideias de uma vida social voltada para o mútuo entendimento e respeito recíproco” (MARTINS; ROESLER; JESUS, 2011, p. 219).

No entender de Bustamante (2008, p. 361-363), a argumentação jurídica é um método de análise racional que abrange todos os aspectos relevantes dos argumentos trazidos para a justificação de uma decisão judicial: normas jurídicas, interpretações dos textos legislativos em geral, enunciados da dogmática, premissas empíricas, estrutura lógica das proposições normativas. Com relação à metodologia jurídica tradicional, as teorias da argumentação jurídica realizam uma ampliação do objeto de estudo, em que os problemas de interpretação fazem parte do raciocínio jurídico. Basicamente, a teoria da argumentação tem uma finalidade, que é tornar a prática jurídica cada vez mais racional e criticamente controlável pela teoria do Direito, mas como toda e qualquer teoria da razão prática, pode atingi-la de forma limitada: “[...] As pautas, diretivas ou regras de argumentação que essas teorias conseguem produzir são, por natureza, incapazes de garantir, sempre, uma única ou, em alguns casos, pelo menos uma - resposta correta para as questões jurídico-aplicativas que venham a tratar."

Embora os autores de argumentação jurídica, com grande frequência, utilizem teoria(s) da argumentação jurídica, a palavra teoria não está associada ao oposto de prática. Percebe-se uma preocupação muito grande com a prática, frequentemente com a decisão judicial e a práxis do Direito de uma maneira geral (BUSTAMANTE, 2008, p. 358).

O contraponto das teorias jurídico-argumentativas seria o positivismo metodológico - em decorrência da subjetividade existente nas interpretações jurídicas, as valorações seriam arbitrárias, negando a possibilidade de uma racionalidade prática. Esse ceticismo constitui o ponto de arranque 
e o paradigma a ser combatido por uma teoria da argumentação jurídica (BUSTAMANTE, 2008, p. 358).

Dessa forma, há a busca por uma ciência do Direito que pretenda instrumentos não só para explicar como se forma uma decisão, mas, sobretudo, para justificá-la. Do “como” para “por que?” (BUSTAMANTE, 2008, p. 360).

Citado por Bustamante (2008, p. 360), Alexy, na Teoria da Argumentação Jurídica, vê uma ciência do direito em três dimensões: 1) analítica, investigando a estrutura do sistema jurídico e de conceitos jurídicos fundamentais, 2) empírica, que se preocupa com o conhecimento do direito positivamente válido e com o uso de certas premissas empíricas e 3) normativa, para orientação e crítica da práxis jurídica, procurando no caso concreto qual a decisão correta baseada no direito válido.

Com isso, é possível associar à existência do Direito, na sua produção, interpretação, aplicação e compreensão, a solução de problemas práticos, que demandam opções e decisões que, por sua vez, para sua sustentação, demandam justificações internas e externas.

\section{CONSIDERAÇÕES FINAIS}

No presente trabalho buscou-se observar oportunidades entre o Direito e a argumentação jurídica, bem como situar a argumentação jurídica no espaço deliberativo, com o resgate de elementos teóricos da argumentação jurídica. Não é possível desenvolver uma teoria da argumentação jurídica que cumpra suas funções teóricas e práticas sem uma adequada análise estrutural do Direito, especialmente compreendendo a vinculação entre os processos argumentativos e o comportamento dos juízes. As relações entre o julgamento jurídico propriamente dito e os julgamentos de natureza moral ou política, bem como os elementos ideológicos e de poder, certamente podem se manifestar no julgamento.

Uma análise de condições matemáticas pode ser muito útil para demonstrar limitações na identificação do Direito por modelos teóricos que buscam atribuir uma explicação necessária ou suficiente sobre a disciplina.

São possíveis e identificáveis inter-relações entre a argumentação jurídica e o direito, especialmente no aspecto argumentativo da decisão judicial. As opções casuísticas associadas ao uso de estratégias para conferir uma aparência de racionalidade à escolha impõem desafios importantes, e a compatibilidade teórica da argumentação jurídica com as premissas da previsibilidade e da segurança pode contribuir com possibilidades de se enfrentar a irracionalidade nas relações 
decorrentes do conflito, no qual há demanda deliberativa, e sua estruturação pelo Direito. Há espaço para convivência complementar de teorias institucionais e argumentação jurídica.

É possível identificar, como resultado, que a argumentação tem por finalidade a geração de razões com consistência, por meio das quais uma pretensão de validade poderia ser rechaçada ou resgatada, as quais se estabelecem nos níveis lógico e semântico e que, portanto, têm convergência com os objetivos de uma proposta teórica de construção de decisões com coerência.

É importante destacar ainda que também é possível, pela argumentação jurídica, reconhecer o significado do discurso racional prático, para uma justificação a partir de exigências da razão geral prática.

\section{REFERÊNCIAS}

AGUILÓ, Josep. Sobre Derecho y Argumentación. In: AGUILO, Josep. Sobre Derecho y Argumentación. Palma (Mallorca): Lleonard Muntaner, 2008.

ALEXY, Robert. Conceito e Validade do Direito. Tradução Gercélia Batista de Oliveira Mendes. São Paulo: Martins Fontes, 2011.

. Constitutional Rights and Proportionality. Revus [Online], 22 - 2014, 25 June 2014. Disponível em: <http://revus.revues.org/2783>. DOI: 10.4000/revus.2783. Acesso em: 12 fev. 2015.

. Sistema jurídico, princípios y razón práctica. Tradução Manuel Atienza. DOXA 5, 1988.

. Teoria de La argumentación jurídica. Tradução Manuel Atienza e Isabel Espejo. 2. ed. Madrid: Centro de Estudos Políticos y Constitucionales, 2007.

. Teoria dos Direitos Fundamentais. Tradução Virgílio Afonso da Silva. 5. ed. alemã, São Paulo: Malheiros, 2008.

. Teoria dos Direitos Fundamentais. Tradução Virgílio Afonso da Silva. 5. ed. alemã, 2. ed. brasileira, São Paulo: Malheiros, 2015.

- The Argument from Injustice. A Reply to Legal Positivism. Translated by Bonnie Litschewski Pauson and Stanley L. Paulson. Oxford: Oxford University Press, 2010.

ATIENZA, Manuel. As Razões do Direito. Teorias da Argumentação Jurídica. Tradução Maria Cristina Guimarães Cupertino. São Paulo: Landy, 2002.

. Curso de Argumentación Jurídica. Madrid: Trotta, 2013.

. El Derecho como argumentación: concepciones de la argumentación. Barcelona: Editora Ariel, 2006.

BUSTAMANTE, Thomas da Rosa de. Teoria do Direito e Decisão Racional. Temas de teoria da 
argumentação jurídica. Rio de Janeiro: Renovar, 2008.

FIGUEROA, ALFONSO G. La Teoría del Derecho en Tiempos de Constitucionalismo. In: CARBONELL, Miguel. Neoconstitucionalismo(s). 2. ed. Madrid: Trotta, 2005.

GUASTINI, Riccardo. La “Constitucionalización” del ordenamiento jurídico: el caso italiano. In: CARBONELL, Miguel. Neoconstitucionalismo(s). 2. ed. Madrid: Trotta, 2005.

GÜNTHER, KLAUS. Teoria da argumentação no direito e na moral: justificação e aplicação. Tradução Claudio Molz. 2. ed. Rio de Janeiro: Forense, 2011.

MACCORMICK, Neil. Argumentação jurídica e teoria do direito. Tradução Waldéa Barcellos. São Paulo: Martins Fontes, 2006.

. Practical Reason in Law and Morality. Oxford: Oxford University Press, 2011.

2008.

. Retórica e Estado de direito. Tradução Conrado Hübner Mendes. Rio de Janeiro: Elsevier,

MARTINS, Argemiro C. M.; OLIVEIRA, Cláudio Ladeira de. A contribuição de Klaus Günther ao debate acerca da distinção entre regras e princípios. Revista Direito GV, v. 2, n. 1, jan-jun 2006, p. 241-254.

MARTINS, Argemiro C. M.; ROESLER, Claudia R.; JESUS, Ricardo A. R. A noção de coerência na teoria da argumentação jurídica de Neil MacCormick: caracterização, limitações, possibilidades. Revista Novos Estudos Jurídicos/UNIVALI, v. 16, n. 2, mai-ago 2011, p. 207-221.

PIETRO SANCHÍS, Luis P. Neoconstitucionalismo y ponderación judicial. In: CARBONELL, Miguel. Neoconstitucionalismo(s). 2. ed., Madrid: Trotta, 2005.

ROESLER, Cláudia R. Os Diversos Enfoques da Teoria Contemporânea do Direito e a Passagem para uma Teoria Constitucionalista do Direito. In: CRUZ, Paulo Márcio; ROESLER, Cláudia R. Direito e Argumentação no Pensamento de Manuel Atienza. Rio de Janeiro: Lumen Juris, 2007.

Theodor Viehweg e a Ciência do Direito: Tópica, Discurso, Racionalidade. Florianópolis: Momento Atual, 2004.

VIANNA, Luiz Werneck. A judicialização da política e das relações sociais no Brasil. Rio de Janeiro: Renavan, 1999.

VIEHWEG, Theodor. Tópica e Jurisprudência. Tradução Tércio S. Ferraz Jr. Brasília: Departamento de Imprensa Nacional, 1979.

\section{DECIDING AND ARGUING: DISCURSIVE RATIONALITY AND THE CENTRAL FUNCTION OF ARGUMENT}




\begin{abstract}
The theme of justification and correction of judicial decisions has led to an even greater interest in understanding the connections between deciding and arguing. Would be possible and identifiable the interrelationships between legal argument and Law? What is the function of the argument in the legal discourse? Initially, given the complexity in defining the outline of Law, there would be opportunities to a complementary stance between Law and legal arguments. In such scenario, this paper was developed in a deductive fashion, by centrally using theoretical elements presented by Manuel Atienza, Klaus Günther, Neil MacCormick and Robert Alexy. The objective was to understand the proposals of legal argumentation, its interrelationship with contemporary Law, and its argumentative role in the construction of justifications for decision options. This work is part of a larger study, which aims to enable the creation and/or implementation of models for analysis and evaluation of legal decisions.
\end{abstract}

\title{
KEYWORDS
}

Principles. Juridical argumentation. Rationality. Judicial decision. 